\title{
Estudo para a caracterização espacial das lacunas no processo de reintegração cromática da pintura $A$ Circuncisão do Menino Jesus
}

\author{
Ana Bailão, Frederico Henriques, Susana Mendes, Alexandre Gonçalves
}

Resumo: O estudo que aqui se apresenta foi efetuado no âmbito do curso de doutoramento em Bens Culturais, na especialidade de Pintura, que decorreu na Universidade Católica Portuguesa, subordinado ao tema da qualidade em reintegração cromática. O objetivo do presente trabalho é propôr um sistema para a caracterização das lacunas da superficie pictórica, direccionado específicamente para o processo de reintegração cromática, de modo a que o conservador-restaurador possa ter acesso a uma informação qualitativa e quantitativa mais rigorosa, antes, durante e depois da intervenção. Para o efeito, utilizaram-se imagens fotográficas de uma pintura sobre madeira do século XVI e um sistema de informação geográfica (SIG). Trata-se de um programa informático utilizado no processamento de dados espaciais, o software open-source QGIS. O projeto tem a particularidade de ter sido efetuado em tempo-real, à medida que a intervenção foi decorrendo, como forma de apoio à tomada de decisão.

Palavras-chave: caracterização de lacunas, reintegração cromática, SIG, QGIS, tomada de decisão

\section{Estudio para la caracterización espacial de lagunas en el proceso de reintegración cromática en la pintura La circuncisión del Niño Jesus}

Resumen: El estudio que aquí se presenta ha sido realizado en el ámbito del programa de doctorado de Bienes Culturales, en la especialidad de Pintura, que tuvo lugar en la Universidad Católica Portuguesa, bajo el tema de la calidad en reintegración cromática. El objetivo de este estudio es proponer un sistema para la caracterización de las lagunas de la superficie pictórica, por lo que el conservador-restaurador puede tener acceso a la información cualitativa y cuantitativa más precisa antes, durante y después de la intervención. Con este fin, hemos utilizado imágenes fotográficas de una pintura sobre tabla (siglo XVI) y un programa informático, un sistema de información geográfica (SIG), que se utiliza en el procesamiento de datos espaciales, el programa QGIS, de código abierto. El proyecto tiene la particularidad de haber sido hecho en tiempo real, durante la intervención, con el fin de apoyar la tomada de decisiones.

Palabras-clave: caracterización de lagunas, reintegración cromática, SIG, QGIS, tomada de decision

\section{Study for spatial characterization of losses for the chromatic reintegration process of the painting The Circumcision of Jesus}

\begin{abstract}
The study presented here was conducted in the framework of the doctoral program in Cultural Heritage, specialization in easel paintings, which took place at the Catholic University of Portugal, upon the theme of quality in chromatic reintegration. The aim of this study is to propose a system for the characterization of the losses in the pictorial surface, so that conservator-restorer can have access to qualitative and quantitative accurate information before, during and after the intervention. We used photographic images of a panel painting from the XVI century and a geographical information system (GIS) software used for processing spatial data, the QGIS open source program. The project has the particularity of being done in real time, during the intervention, in order to support the decision-making process.
\end{abstract}

Keyword: characterization of losses, chromatic reintegration, GIS, QGIS, decision-making 


\section{Introdução}

Neste estudo, aplicado a uma pintura sobre madeira, designada por A Circuncisão do Menino Jesus em itálico pertencente à coleção privada do Seminário Maior de Nossa Senhora, no Porto, propõe-se demonstrar a aplicação e o uso de uma ferramenta de análise espacial para a caracterização de lacunas durante a fase de reintegração cromática, como forma de apoio à tomada de decisão. $O$ principal objetivo é a documentação e o registo das lacunas de forma qualitativa, quantitativa e rigorosa. Esta informação não é somente útil durante a intervenção, mas também na primeira fase de projeto e diagnóstico, constituindo um documento essencial de análise da obra após a conclusão da intervenção. $O$ sistema apresentado possibilita o registo individualizado de cada lacuna - por parte do conservador-restaurador responsável pela reintegração - da metodologia, da técnica e dos materiais utilizados. Em certa medida, poderá ser, no futuro, uma ferramenta nuclear para o processo de verificação e avaliação de qualidade, que deve ser efetuado sempre e após uma intervenção pelo conservador-restaurador.

A "reintegração cromática tradicional", corrente no século XIX, implicava a reinvenção e raramente se restringia aos limites da lacuna, convertendo-se facilmente em repinte. Todavia, a consciência histórica alcançada a partir do século XX recomenda que a autenticidade das obras do passado seja respeitada (Mora, Mora, Philippot, 1984: 301), assim como a criatividade do autor, não podendo por isso ser reproduzida, mas apenas interpretada de um modo crítico (Philippot, Philippot, 1959:5; IDEM, Ibidem em itálico). Isto significa que a operação de reintegração cromática deve parar quando a hipótese começa.

Sobre a especificidade e particularidades das intervenções de reintegração cromática, depois da análise espacial das lacunas, com o método apresentado e, no decurso da tomada de decisão, importa ressalvar que o conhecimento acerca da tipologia das lacunas pode implicar uma avaliação gestaltista (Bailão, 2010: 128-139). Um processo considerado essencial para o entendimento de cada uma das lacunas presentes na obra. Contudo, a correlação da apreciação gestalista, associada à análise métrica com parametrização de percentagens de área, podem, segundo os autores, revelar-se instrumentos de suporte essenciais ao planeamento da intervenção da reintegração cromática.

\section{Tipologia de Lacunas}

Em linhas gerais, para reconhecer a tipologia de lacunas é necessário reconhecer um método de análise passível de ser utilizado como referencial de interpretação. No presente trabalho, numa primeira fase de análise, optámos por recorrer ao trabalho que resultou das reflexões de Paolo Mora, Laura Mora e Paul Philippot sobre as tipologias de lacunas (Mora, Mora, Philippot, 1984: 305-315).
Se bem que tais reflexões tenham sido direcionadas para a problemática e especificidade da pintura mural, é possível, com as devidas ressalvas, observar o problema de acordo com o estrato pictórico (ou policromia) e tais lacunas podem ser divididas em cinco tipos diferentes. Para essa parametrização, sistematizada aqui como de tipo I, II, III, IV e V, devem-se ter em linha de conta a localização, a dimensão ou extensão e a profundidade com que as lacunas atravessam os estratos pictóricospictórico [ver Tabela 1]:

Para os autores acima referidos, nas lacunas Tipo $\mathrm{V}$, exige-se uma intervenção onde se deve preservar o valor histórico, com eventual reconstrução, mas sempre discernível. Após a análise das cinco tipologias indicadas, é possível verificar que a caracterização das lacunas é feita, sobretudo, em função da perda verificada. Parâmetros como a localização, extensão em superfície e profundidade da lacuna são sumariamente referidos, embora sejam essenciais para a caracterização das lacunas, uma vez que podem comprometer ou favorecer (no caso das lacunas com suporte à vista) a interpretação da imagem pictórica. $\mathrm{Na}$ presença de lacunas Tipo V, para os autores Paolo Mora, Laura Mora e Paul Philippot, deve-se preservar o valor histórico, com eventual reconstrução, mas sempre discernível. Como contributo para o enquadramento teórico-prático, equacionam-se cinco situações [Figura 1]:

1. Lacunas pouco extensas que devido à sua localização, podem ser reconstruidas com técnicas miméticas ou diferenciadas;

2. Lacunas pouco extensas que devido à sua localização não devem ser reconstruídas (ausência de informação formal);

3. Lacunas que devido à sua localização não devem ser reconstruídas;

4. Lacunas que devido à sua extensão e localização não devem ser reconstruídas;

5. Lacunas que, embora extensas, podem ser reconstruídas, por se situarem em áreas de composição pictórica com padrões e valores cromáticos e formais evidentes, que não coloquem dúvidas na interpretação.

As tipologias de lacunas enunciadas são interpretadas de um modo diferente por Umberto Baldini (Baldini, 1998: 22). Para o historiador, existem dois tipos de lacunas: a "lacuna-perda" e a "lacuna-falta".

A primeira tipologia de lacuna, a"lacuna-perda", caracterizase pela separação total e permanente de uma determinada parte da obra associada ao destacamento, dano ou ruína. Na prática, numa superfície pintada, a "lacuna-perda" será a ausência total de cor, de imprimadura [2] e de preparação. Isto significa que o suporte (tela, madeira ou metal) está à vista do observador.

A "lacuna-falta"corresponde aos fenómenos de degradação na camada cromática como a rede de microfissuras, as abrasões ou desgastes, entre outros (IDEM, Ibidem). Nesta 


\begin{tabular}{|c|c|c|}
\hline Tipologia & Característica da tipologia de lacuna & Soluções apresentadas pelos autores \\
\hline $\begin{array}{l}\text { Tipo I } \\
\text { (desgaste) }\end{array}$ & Desgaste da pátina. & $\begin{array}{l}\text { Poderá ser solucionado através de uma reintegração por } \\
\text { velatura a aguarela, que deverá ser no tom da pátina }\end{array}$ \\
\hline $\begin{array}{l}\text { Tipo II } \\
\text { (desgaste) }\end{array}$ & $\begin{array}{l}\text { Desgaste da camada pictórica (desgaste que resultou de } \\
\text { um fator externo, uma ação física, ou ausência diminuta } \\
\text { de perca de material ocasionada por alterabilidade do } \\
\text { tipo de pulverulência). }\end{array}$ & $\begin{array}{l}\text { Poderá ser solucionado com uma velatura mais clara e fria } \\
\text { que o tom original. }\end{array}$ \\
\hline $\begin{array}{l}\text { Tipo III } \\
\text { Lacuna (camada pictórica) }\end{array}$ & $\begin{array}{l}\text { Lacunas na camada pictórica, pouco extensas, bem } \\
\text { limitadas em área, passíveis de serem reconstruídas. }\end{array}$ & $\begin{array}{l}\text { Possibilidade de reconstrução com técnicas diferenciadas, } \\
\text { sugerindo os autores, Paolo e Laura Mora e Philippot, o } \\
\text { tratteggio [1]. }\end{array}$ \\
\hline $\begin{array}{l}\text { Tipo IV } \\
\text { Lacuna (camada pictórica) }\end{array}$ & $\begin{array}{l}\text { Lacunas extensas na camada pictórica com perca total da } \\
\text { matéria. }\end{array}$ & $\begin{array}{l}\text { Pela sua extensão e localização não devem ser } \\
\text { reconstruídas. }\end{array}$ \\
\hline $\begin{array}{l}\text { Tipo V } \\
\text { Lacuna (camada pictórica) }\end{array}$ & $\begin{array}{l}\text { Lacunas de considerável extensão que colocam em causa } \\
\text { o significado arquitetónico das cenas. }\end{array}$ & $\begin{array}{l}\text { Devido à importância que estas lacunas têm para a } \\
\text { totalidade da obra, independentemente da extensão, } \\
\text { podem ser reconstruídas. São exemplo os marmoreados, } \\
\text { o trompe l'oeil em itálico, as composições ilusionistas e } \\
\text { os elementos decorativos. Apesar de não existirem regras } \\
\text { universais de atuação, as reintegrações podem assumir } \\
\text { uma vertente conservativa, arqueológica, e, em alguns } \\
\text { casos, reconstrutiva. O processo poderá ser feito com } \\
\text { uma técnica próxima do original, em tom mais claro e } \\
\text { frio, sempre circunscrito à área da lacuna, mas discernível } \\
\text { quando observado de perto. }\end{array}$ \\
\hline
\end{tabular}

Tabela 1.- Interpretação da relação das tipologias de lacunas e soluções apresentadas por Paolo Mora, Laura Mora e Paul Philippot, no contexto das intervenções de reintegração cromática em pintura mural (Mora, Mora, Philippot, 1984: 305-315).

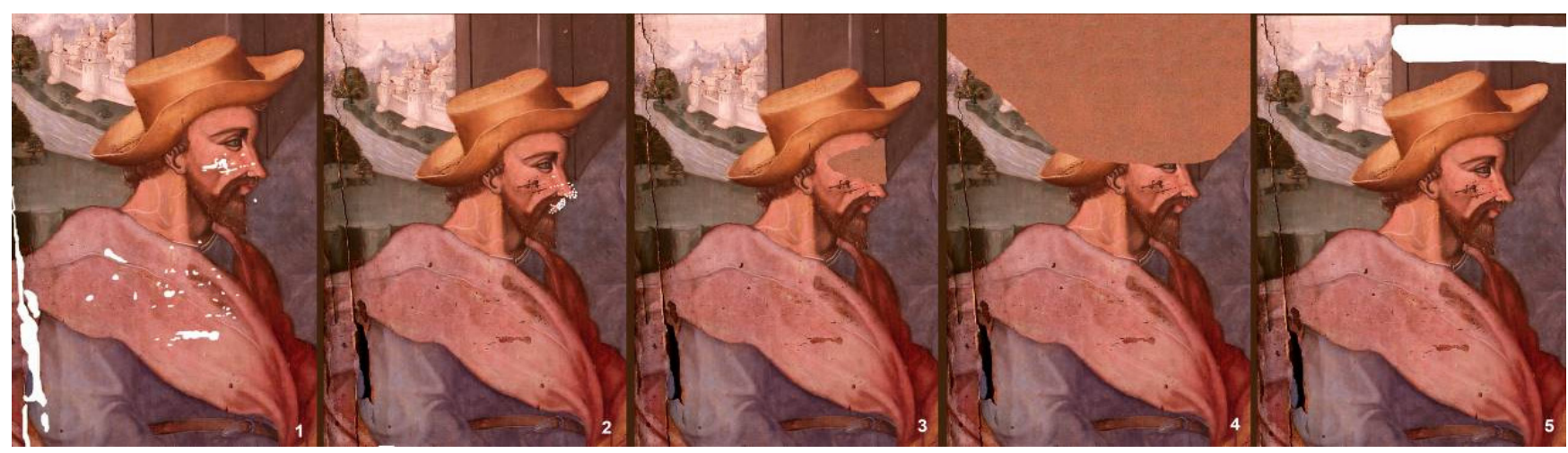

Figura 1.- No contexto do painel em análise, simulação das cinco tipologias de lacunas. Esquema gráfico de Ana Bailão.

situação, para Baldini, não é necessária nenhuma ação, uma vez que é preferível deixar a matéria original evidenciar o seu percurso na história (a sua degradação), designado por Baldini como "tempo de vida", em vez de efetuar uma reintegração que falsifique este percurso e diminua a originalidade do bem cultural.

A intervenção sucede quando a obra apresenta a "lacunaperda". Estando presente esta tipologia de lacuna, podem ocorrer, de acordo com Baldini, duas situações: quando existem referências formais e cromáticas, utiliza-se o método de seleção cromática [3]; quando não existem estes dados opta-se pelo método de abstração cromática [4] (Ciatti, 2009: 24) [Tabela 2]

No seguimento da análise de classificação de Mora, Mora e Philippot, e de Umberto Baldini, pode-se concluir que, quando estamos perante lacunas, podemos ter dois tipos de posições:

a) Uma posição mais pragmática de Paolo e Laura Mora e de Paul Philippot para a solução do problema, que se caracteriza por uma noção espacial da extensão das lacunas com aplicabilidade prática na perceção da imagem e na intervenção da obra. 
b) Uma posição de vertente epistemológica de Umberto Baldini, que consiste na análise da tipologia de lacuna em função da sua origem e aparecimento, existindo apenas duas soluções viáveis: seleção cromática ou abstração cromática. A aplicabilidade prática desta proposta é mais limitada, uma vez que a última técnica citada nem sempre resulta agradável do ponto de vista visual, pelo facto de realçar demasiado a intervenção realizada quando observada de longe ou de perto, e pelos diversos fenómenos de gestaltismo que condicionam a perceção do observador.

O fenómeno gestaltista foi primeiramente investigado pelo psicólogo dinamarquês Edgar Rubin e mais tarde correlacionado ao património por Cesare Brandi. Segundo o historiador, no contexto de uma imagem, a lacuna, perante a perceção espontânea do observador, é vista como uma "figura", enquanto a composição pictórica é visualizada como "fundo". E é essa relação entre "figura-fundo" que está na base da perceção sensorial associada à caraterização das lacunas, quando se observa um objeto.

Importa referir novamente que a interpretação das lacunas neste estudo teve como ponto de partida as tipologias de lacunas indicadas por Paolo Mora, Laura Mora e Paul Philippot, com a apreciação e a avaliação das lacunas de acordo com os seguintes parâmetros: a localização, a extensão e a profundidade da lacuna. A opção pela intervenção ou não intervenção, assim como a eleição da técnica de reintegração cromática dependeu,

\begin{tabular}{|l|l|}
\hline \multicolumn{1}{|c|}{ TIPOLOGIA } & \multicolumn{1}{c|}{ SOLUÇÃO } \\
\hline $\begin{array}{l}\text { Tipo I: } \\
\text { Lacuna perdida }\end{array}$ & $\begin{array}{l}\text { • Abstração cromática (sem referências) } \\
\text { • Seleção cromática (com referências }\end{array}$ \\
\hline $\begin{array}{l}\text { Tipo II: } \\
\text { Falta (fissuras ou } \\
\text { abrasões) }\end{array}$ & • Não se faz nada \\
\hline
\end{tabular}

Tabela 2.- Relação das tipologias de lacunas e soluções apresentadas por Umberto Baldini (Baldini, 1998: 22). também, desta apreciação. De seguida, esquematizamse os fatores considerados em cada parâmetro [Tabela 3]:

Os pontos elencados na Tabela 3, associados aos três parâmetros (localização, extensão e profundidade) podem ser interpretados, em pinturas de caráter figurativo, em função das composições pictóricas, da existência de figuras, da presença de arquiteturas, dos fundos apresentarem um trabalhado simples ou de detalhe e da dimensão da pintura.

Se excluirmos as lacunas de desgaste (Tipo I e II), a área lacunar da pintura intitulada A em itálico Circuncisão do Menino Jesus não era significativa, existindo pequenas lacunas ao nível da camada cromática, do preparo e do suporte, localizadas em carnações, em panejamentos, na arquitetura e na paisagem de fundo. A presença destas lacunas não afetava a leitura da composição pictórica, nem tinha mais protagonismo do que a obra. Existiam ainda lacunas ao nível do suporte lenhoso, de maior dimensão, em extensão e profundidade, que, por se localizarem em zonas de panejamento castanho, integravam-se perfeitamente com a camada cromática original.

Para reforçar e ilustrar a descrição supra mencionada, recorreu-se a uma ferramenta informática de sistemas de informação geográfica (SIG). Esta plataforma permitiu a visualização e a análise qualitativa e quantitativa das lacunas presentes na pintura sobre madeira em estudo.

\section{Caracterização de lacunas através de análise métrica}

A caracterização de lacunas pode ser efetuada através da análise métrica utilizando ferramentas da georreferenciação, uma técnica utilizada em caracterização e ordenamento de território com sistemas de informação geográfica [5]. Para este ensaio académico recorreu-se a um programa informático open-source, denominado QGIS, na versão 2.6.0 (Brighton). Como estudo de caso, utilizou-se uma pintura a óleo sobre madeira, proto-maneirista, denominada A Circuncisão do Menino Jesus, com as seguintes dimensões: $204 \mathrm{~cm} \mathrm{x}$

\begin{tabular}{|l|l|l|}
\hline \multicolumn{1}{|c|}{ Extensão } & \multicolumn{1}{c|}{ Localização na cena pictórica } & \multicolumn{1}{c|}{ Profundidade } \\
\hline $\begin{array}{l}\text { - Medida em percentagem de área da } \\
\text { lacuna em comparação com a área total } \\
\text { da obra. }\end{array}$ & $\begin{array}{l}\text { - Carnação; } \\
\text { - Panejamento; } \\
\text { - Arquitetura; } \\
\text { - Paisagem; } \\
\text { - Áreas centrais; } \\
\text { - Áreas marginais à representação } \\
\text { pictórica; } \\
\text {-e não; }\end{array}$ & $\begin{array}{l}\text { - Desgaste da camada de pátine; } \\
\text { - Desgaste na camada pictórica; } \\
\text { - Lacunas da camada pictórica; } \\
\text { - Lacunas que incluem tanto a camada } \\
\text { pictórica como o preparo. }\end{array}$ \\
\hline
\end{tabular}

Tabela 3.- Caracterização de lacunas em função da localização, extensão e profundidade. 
149,2 cm. Trata-se de uma obra de oficina desconhecida, proveniente, presumivelmente, da Igreja de Rossas, em Arouca, e que incorpora na atualidade a coleção privada do Seminário Maior de Nossa Senhora da Conceição, no Porto [6].

Acerca do painel, sabe-se que, em 1600, existia na Igreja de Rossas uma obra com a representação da "Circuncisão", e que era da mesma autoria do retábulo principal, encomendado por Frei Duarte de Brito, em 1600. Numa transcrição contemporânea de parte do livro de Visitações sobre a igreja, realizada por António Brandão de Pinho (estudioso dedicado à história da paróquia e freguesia de Rossas), refere-se que:

[...] e no alto dele [retabolo] esta hua pintura da Virgem Snra Nossa que he Padroeira desta Comda, no meyo do dicto retabolo esta hum letreiro da qual consta que o Com.dor Fr. Duarte de Brito Pr.a mandou fazer esta obra no anno de 1600. Tem esta Igr.a do arco a fora dous Altares collecteraes com dous retabolos de obra de boa talha e dourados de ouro sobre azul; e no da parte do Evang.o esta hua Imagem de Vulto de Sam Sebastiam, e junto delle esta pregado na parede hum painel da circumcizam de Christo Snr Nosso, e que mostra ser feito p.lo mesmo Pintor, que fes os painéis do retabolo da Capp.a Mor [...] (Visitações Gerais da Ordem de Malta à Comenda de Rossas [Manuscrito], 1718-1719: 68).

Na fase de processamento digital do presente trabalho, através da utilização do programa informático de uso livre, QGIS 2.6.0. Brighton, foi realizado o mapeamento e a quantificação de lacunas [figura 2]. Neste exercício, a identificação de lacunas fez-se em modo de edição vetorial, de forma não automática, com base na fotointerpretação da imagem da obra. As lacunas analisadas foram especificamente as que, nas tipologias de Paolo Mora, Laura Mora e Paul Philippot, se enquadram no tipo III e IV. Importa referir que, pelo facto de a proposta de intervenção não contemplar a reintergração cromática sob a forma de velatura, as lacunas do tipo I e II não foram vetorizadas.

Quanto ao tipo de análise com o SIG, importa referir que, em vez do modelo de representação vetorial, também se pode usar o modelo de representação matricial, orientado ao píxel. E quanto a este último tipo de análise, são conhecidas algumas abordagens noutros estudos. Veja-se, por exemplo, os casos da pintura quinhentista $O$ Calvário, do Museu Nacional Machado de Castro, Coimbra (Henriques, Gonçalves, Calvo, Bailão, 2011: 234-236) e da pintura mural do arco triunfal da Charola, do Convento de Cristo, em Tomar (Henriques, Gonçalves, Calvo, Bailão, 2009: 13-15) [7]. No entanto, esta investigação foi estritamente direcionada para o modelo de representação de tipo vetorial (ponto, linha e polígono).

No decurso das operações, a análise espacial da composição pictórica da pintura seiscentista sobre madeira, $A$ Circuncisão do Menino Jesus, permitiu contabilizar 1091 lacunas de forma e extensão variadas, que representam $3 \%$ da área total da obra [figura 3 e 4].

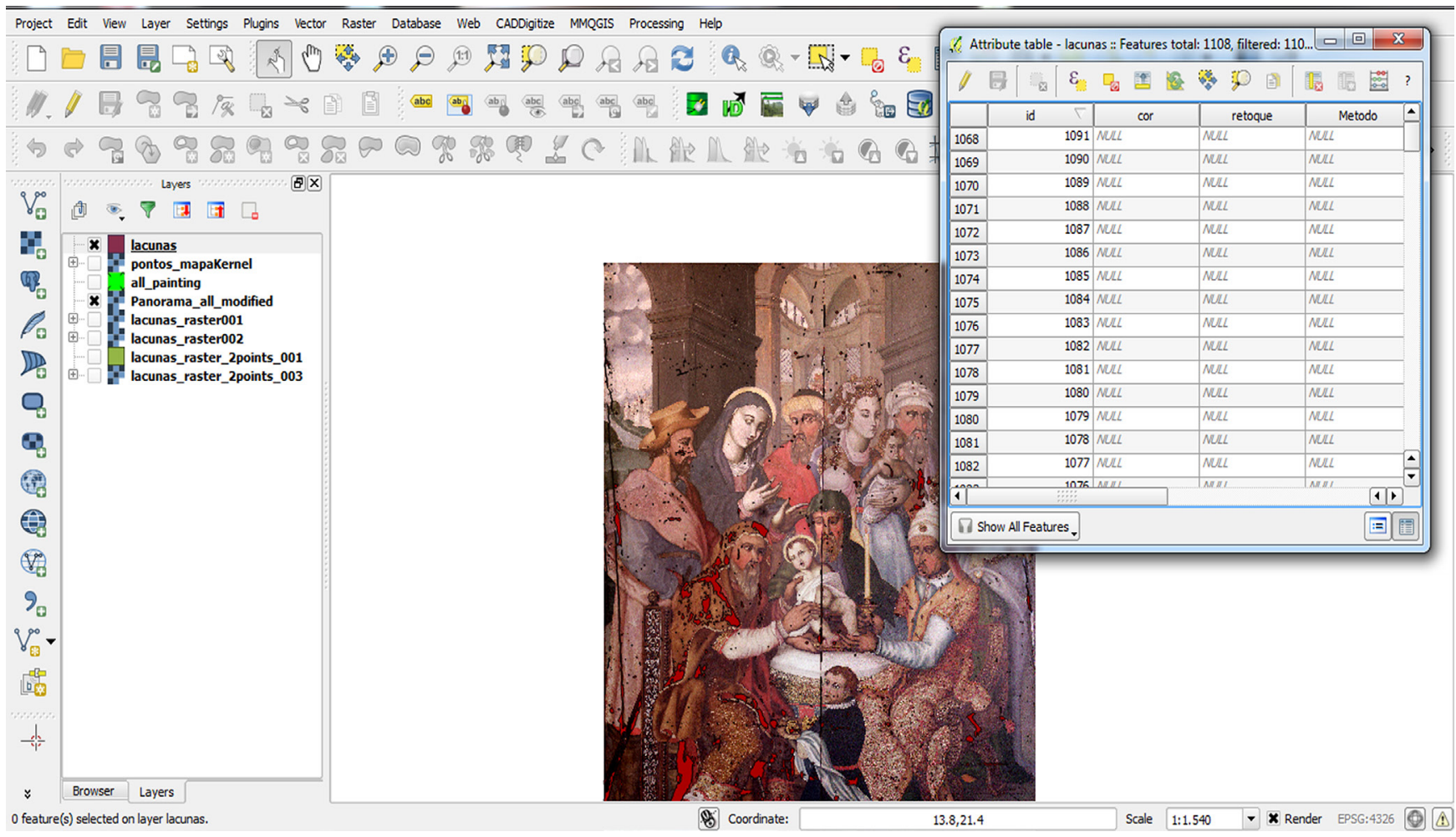

Figura 2- Visualização do interface gráfico e da pintura durante o processamento das lacunas no programa QGIS. Esquema gráfico de . 

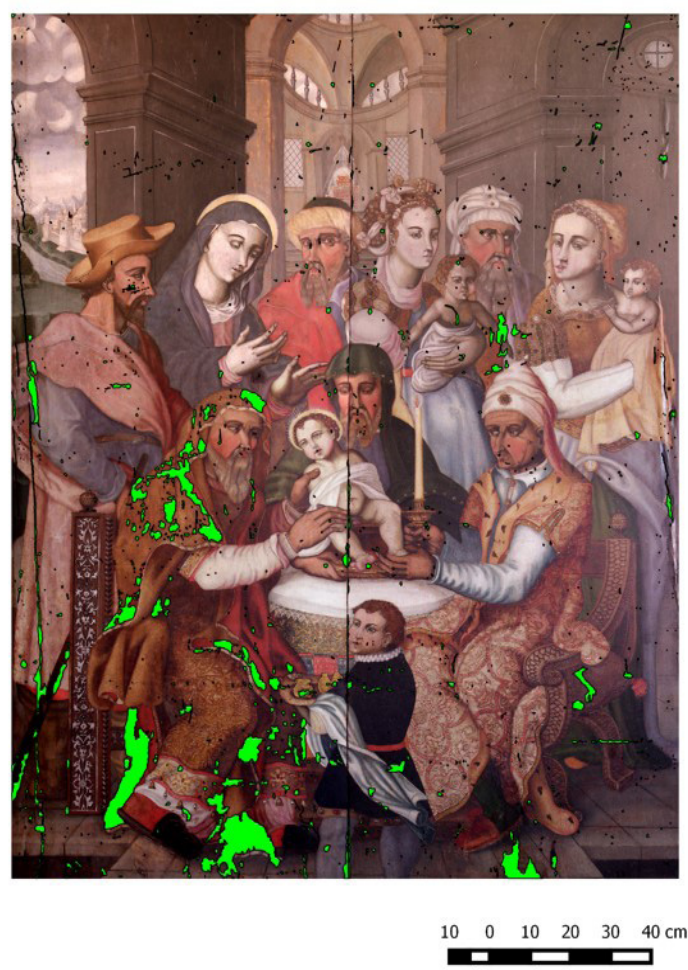

Figura 3- Visualização da imagem da pintura com indicação das lacunas a verde. $\mathrm{O}$ tom verde das lacunas resultou de um processamento digital com o programa informático QGIS

Numa apreciação do mapa temático produzido, a área lacunar é manifestamente de pouca extensão. A maioria das lacunas são muito pequenas e situam-se em zonas marginais à representação pictórica. Apenas 38 lacunas, que se estendem até ao suporte lenhoso, assumem maiores dimensões.

Com esta ferramenta foi possível projetar e obter a seguinte informação:

- Quantificação percentual da área que as lacunas ocupam na superfície pictórica;

- Quantificação precisa do número de lacunas;

- Classificação métrica e indicação espacial da localização das respetivas lacunas;

- Estimativa do número de horas afetas à reintegração cromática, calculada através dos valores de área;

- Criação de uma tabela de atributos com informação alfanumérica associada a cada lacuna, nas quais se pode especificar, por número de identificação da lacuna, a técnica de reintegração, as cores e os materiais utilizados na concretização da tarefa.

Neste ensaio, determinou-se que, na pintura $A$ Circuncisão do Menino Jesus, as lacunas estão distribuídas do seguinte modo:

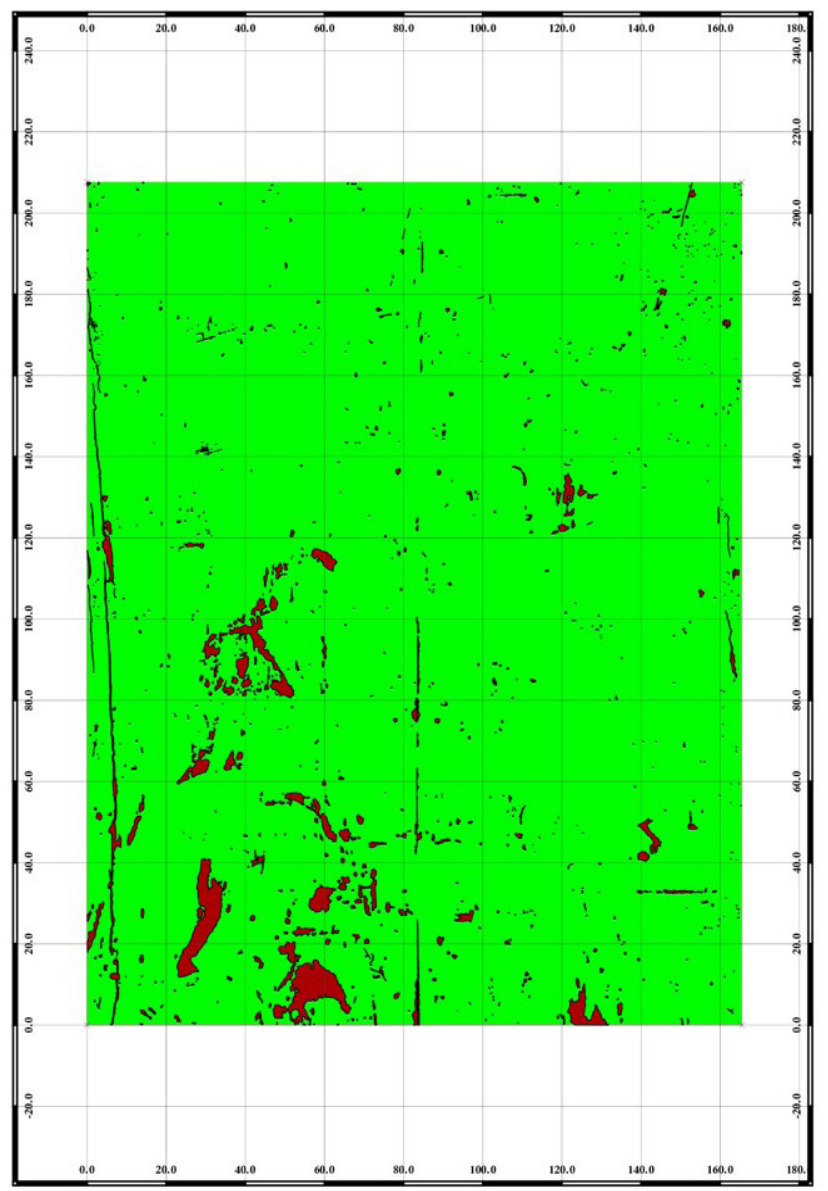

Figura 4- Mapa temático que indica a distribuição espacial das lacunas. Esquema gráfico de Ana Bailão.

\begin{tabular}{lll}
$>0.4 \%$ & $\operatorname{RGB}(255,25,23)$ \\
$0.1 \%$ a $0.4 \%$ & $\operatorname{RGB}(255,127,0)$ \\
$0.01 \%$ a $0.1 \%$ & $\operatorname{RGB}(255,246,3)$ \\
$<0.01 \%$ & $\operatorname{RGB}(186,221,105)$ \\
\hline
\end{tabular}

Tabela 4- Escalas de cor com intervalos para caracterização da área lacunar e informação específica de parâmetros RGB. Esquema gráfico de Ana Bailão.

-Existem 5 lacunas de maiores dimensões, que ocupam áreas de $0,1 \%$ a $0,4 \%$ e que correspondem a $1,2 \%$ da área total da pintura;

-Existem 33 lacunas de tamanho médio, que ocupam áreas entre 0,01\% a 0,08\% e que correspondem a $0,9 \%$ da área total;

—Existem 1053 lacunas pequenas, que ocupam individualmente áreas menores que 0,009\% e que em conjunto correspondem a $0,9 \%$ da área total da obra.

A seleção da tipologia de lacunas fez-se por intervalos de percentagem [8], que se ajusta em função da dimensão do objeto [tabela 4]. Para facilitar a interpretação dos 
dados, propõe-se uma escala de cores [9] com 4 classes: vermelho (área elevada), laranja (área grande), amarelo (área média) e verde (área pequena).

No caso da pintura A Circuncisão do Menino Jesus apenas se verificaram 3 classes, o intervalo laranja, o amarelo e o verde, não se verificando lacunas de tamanho elevado, acima de 0,4\% [figura 5].

Com base nos dados obtidos com o QGIS e refletindo nos parâmetros indicados ao longo do texto, pode-se concluir o seguinte:

1- Em relação à extensão, as lacunas da pintura $A$ Circuncisão do Menino podem ser classificadas em três classes:

- 1,2\% correspondem a 5 lacunas de maiores dimensões:

- 0,9\% correspondem a 33 lacunas de tamanho médio;

- 0,9\% correspondem a 1053 lacunas de pequeñas dimensões.

2- Em relação à localização e profundidade das lacunas pode dizer-se o seguinte [figura 6 e tabela 5]:
- 1044 lacunas são pouco extensas e poderiam ser reintegradas por se situarem em áreas de composição pictórica com padrões e valores cromáticos e formais evidentes, que não colocam dúvidas na interpretação.

- 9 lacunas, mais extensas, poderiam colocar problemas durante a reintegração, por se situarem em áreas de composição pictórica que colocariam dúvidas, nomeadamente associadas à extensão das sombras, das luzes e da gradação de cor entre o vermelho e o castanho. No entanto, são lacunas que se estendem ao nível do suporte lenhoso e se localizam numa zona de panejamento castanho, passando, por isso, despercebidas ao observador (a uma distância de 2 a 3 metros), em contexto museológico. $\mathrm{O}$ mesmo acontece com as 3 lacunas de maiores dimensões, com a identificação na tabela de atributos, de ID n.o 48, 118 e 501, não sendo necessária, na opinião dos autores, qualquer reintegração cromática para valorização da interpretação da obra.

Após a análise supra da distribuição e quantificação de perdas, depreende-se que, pelo facto de algumas zonas da pintura apresentarem uma tonalidade geral acastanhada, próximo da cor do suporte, a maioria das lacunas
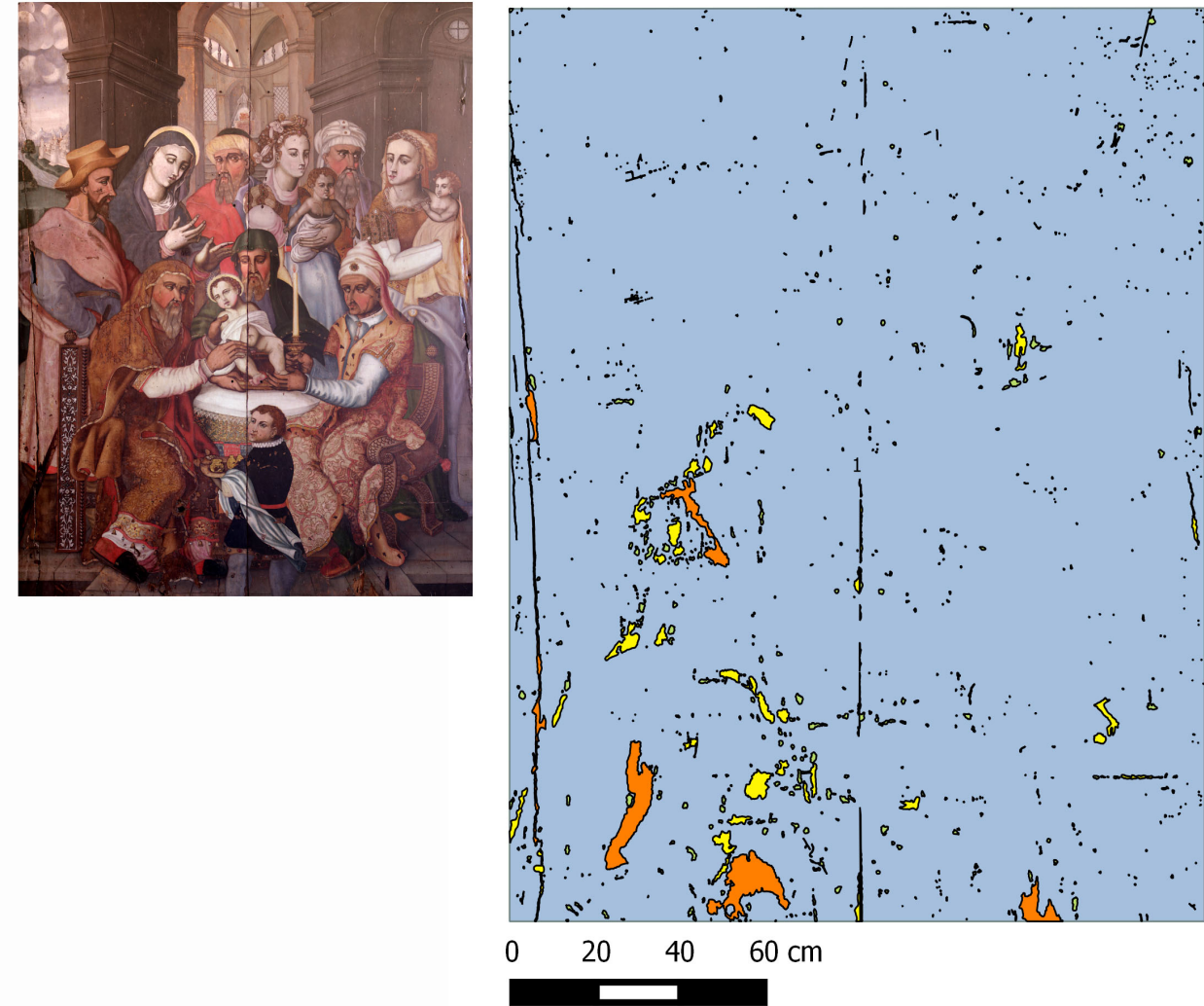

TABELA DE ATRIBUTOS

\begin{tabular}{|l|l|l|l|}
\hline id & AREA & AREA_TOTAL & AREA_PERC \\
\hline 1 & 1.434177 & 34346.404905 & 0.004176 \\
\hline 3 & 6.038407 & 34346.404905 & 0.017581 \\
\hline 2 & 0.089651 & 34346.404905 & 0.000261 \\
\hline 9 & 0.334124 & 34346.404905 & 0.000973 \\
\hline 8 & 0.510512 & 34346.404905 & 0.001486 \\
\hline 7 & 0.114704 & 34346.404905 & 0.000334 \\
\hline 6 & 0.291385 & 34346.404905 & 0.000848 \\
\hline
\end{tabular}

\section{LEGENDA}

Classificação de lacunas por percentagem de área

$(0.358 \%-0.115 \%)$ $(0.076 \%-0.010 \%)$ $\square(<0.009 \%)$

Número de lacunas: 1091 Percentagem total de lacunas: $3 \%$

Figura 5- Composição gráfica com imagem fotográfica da pintura, um mapa das lacunas e respetiva tabela de atributos. No que diz respeito à classificação de lacunas por percentagem de área, o valor estimado foi de $3 \%$ da área total, num total de 1091 lacunas. No mapa temático das lacunas podem-se observar a localização e a distinção cromática entre lacunas de pequena, média e maiores dimensões. A tabela de atributos dá como exemplo seis lacunas, a indicação da área específica de cada lacuna, da área total da obra e a respetiva percentagem. Esquema gráfico de Ana Bailão. 
confundia-se com o manto e não ganhava protagonismo. Neste caso, o fenómeno gestaltista de "figura-fundo" não foi tão evidente [10]. Através de uma análise detalhada da obra, chegou-se à conclusão que, para este ensaio, se podia prescindir da ação de reintegração na generalidade das lacunas [figura 7], tendo-se selecionado somente 40 lacunas para eventual intervenção. As lacunas que assumiam maior protagonismo eram as longitudinais e as de forma arredondada que, na sua maioria, se localizavam em rostos ou em zonas em que as cores, em torno da lacuna, realçavam a cor do suporte perante o observador

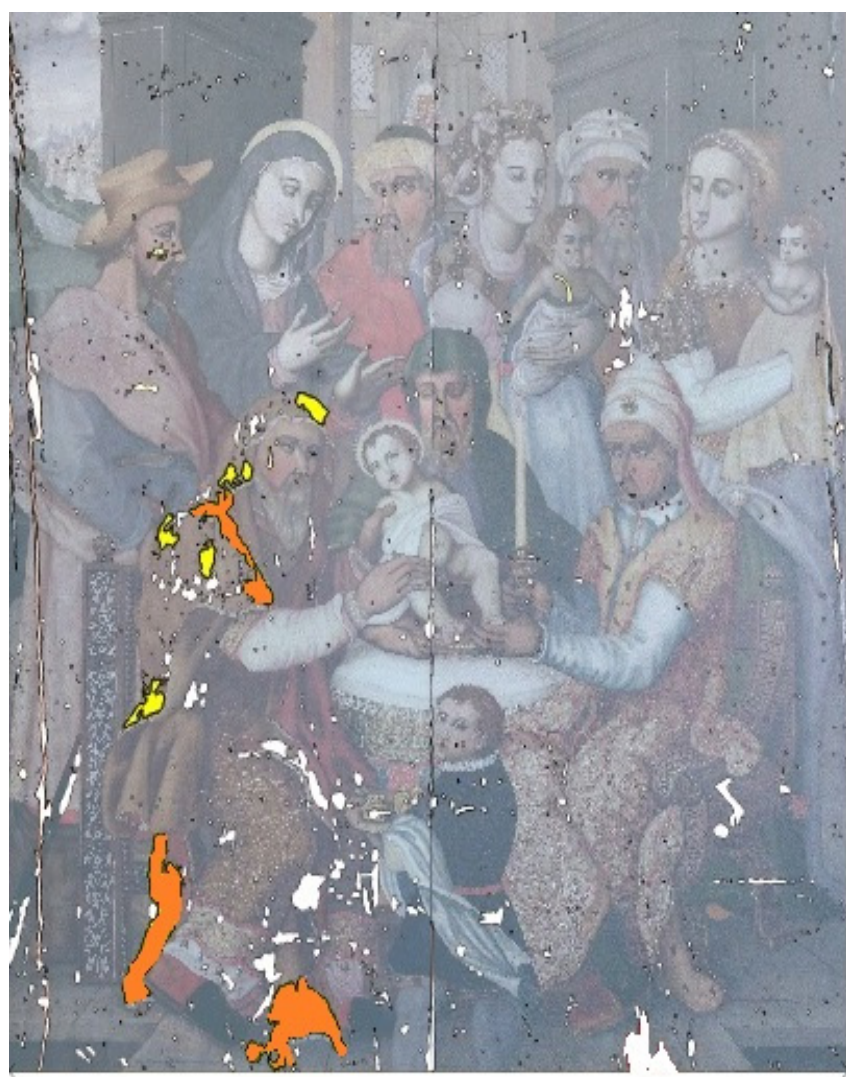

Figura 6- Localização das 9 lacunas que podem suscitar dúvidas no momento da intervenção comum. Eram lacunas de cores e formas homogéneas, minimizando, assim, as interpretações dúbias, quer em relação às gradações dos tons e reprodução das sombras e das luzes, quer na continuidade de linhas ou fisionomias.

Para além da classificação de lacunas, calculada por percentagem de área de ocupação na totalidade da obra, e calculada em $\mathrm{cm}^{2}$ de cada lacuna, fez-se também, no contexto da investigação e estudo da obra, uma estimativa de horas afetas à componente prática da reintegração cromática [11]. Esta estimativa foi efetuada após a reintegração a aguarela de uma lacuna. Se bem que o tempo que cada conservador-restaurador demora a fazer o acerto de uma cor seja sempre uma questão subjectiva, este teste permitiu avaliar o tempo necessário para a conclusão das bases cromáticas [12], mediante a reintegração de uma lacuna, por parte da responsável pela intervenção. Como técnica de reintegração optou-se pelas
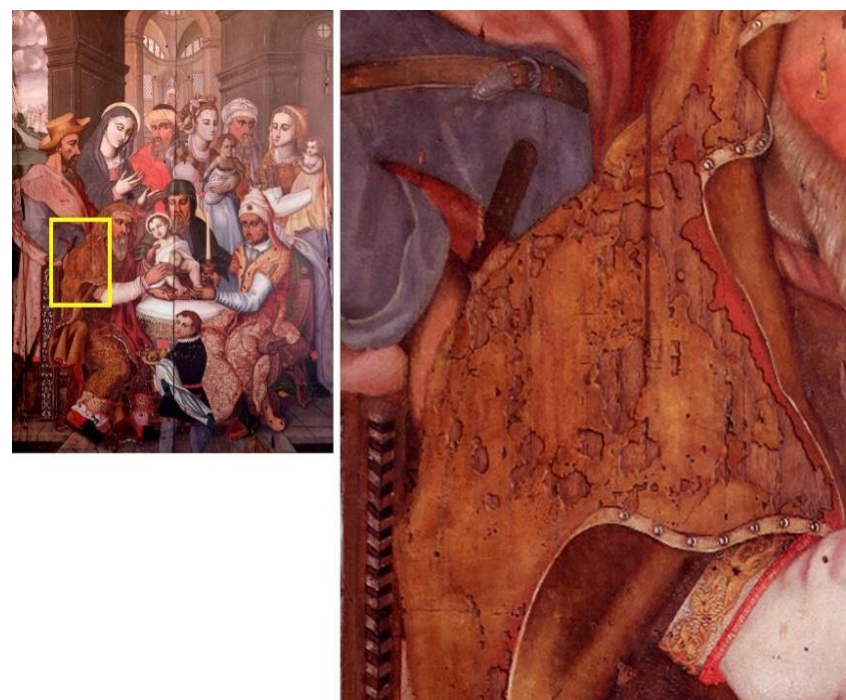

Figura 7- Vista geral da pintura A Circuncisão do Menino Jesus. Pormenor de um manto onde se pode verificar que, devido à proximidade tonal da cor da camada cromática e do suporte lenhoso, as lacunas, durante a observação, são remetidas para segundo plano. Fotografias e esquemas gráficos dos autores.

\begin{tabular}{|r|r|r|l|l|l|}
\hline id & AREA & AREA_PERC & TEC_REINTG & Matizes & MATIZES \\
\hline 48 & 123.070393 & 0.358321 & Sem Reintegração & sem indicação & - \\
\hline 421 & 118.467230 & 0.344919 & Sem Reintegração & sem indicação & - \\
\hline 474 & 22.584074 & 0.065754 & Sem Reintegração & sem indicação & - \\
\hline 540 & 12.745410 & 0.037108 & Sem Reintegração & sem indicação & - \\
\hline 521 & 16.658862 & 0.048502 & Sem Reintegração & sem indicação & - \\
\hline 52 & 4.971687 & 0.014475 & Sem Reintegração & sem indicação & - \\
\hline 512 & 7.829789 & 0.022797 & Sem Reintegração & sem indicação & - \\
\hline 501 & 11.710260 & 0.034095 & Sem Reintegração & sem indicação & - \\
\hline
\end{tabular}

Tabela 5- Assinala-se a laranja as três lacunas com perda de material ao nível do suporte. Excerto da tabela de atributos com apresentação de apenas 9 lacunas. Na primeira coluna temos o n. ${ }^{\circ}$ de ID, na segunda coluna está a indicação da área específica e na terceira coluna está a área percentual de cada lacuna. 
bases planas, ao tom da madeira, tendo sido aplicadas duas camadas de cor.

Através do valor de tempo despendido numa determinada área foi possível calcular o tempo necessário para a restituição cromática da restante área lacunar. Foi escolhida a lacuna $n .^{\circ} 243$, previamente preenchida com massa de preenchimento, e com uma área de $39,5 \mathrm{~cm}^{2}$. A reintegração demorou 36 minutos a finalizar. Com estes dados foi possível calcular uma estimativa para a totalidade de lacunas $\left(913,1 \mathrm{~cm}^{2}\right)$ ou apenas para as 40 lacunas que se pretendia reintegrar na fase inicial do projeto $\left(139,4 \mathrm{~cm}^{2}\right)$ [figura 8]. É importante referir que a área total da obra é $30.436,8 \mathrm{~cm}^{2}$.

Para estimar o número de horas necessário para a realização da reintegração, recorreu-se a uma regra de

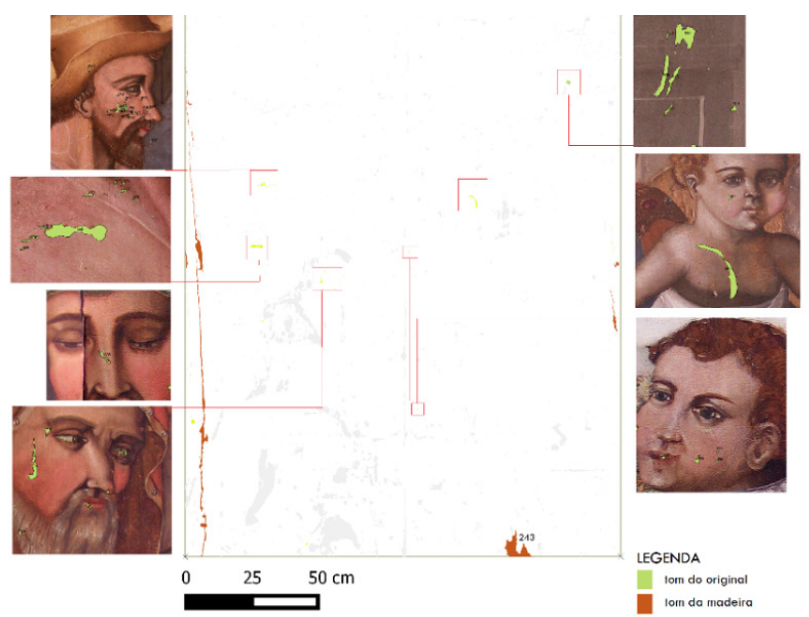

Figura 8- De modo esquemático apresentam-se as regiões selecionadas na fase de projeto para a reintegração cromática. Nas sete regiões indicadas do esquema, as lacunas encontram-se reintegradas virtualmente a verde. Nesta vista global do mapa de perdas, a lacuna $n^{\circ} 243$ foi a escolhida para o teste cromático e está localizada na zona inferior direita da obra Esta lacuna serviu de base para a estimativa e cálculo das horas necessárias para a conclusão da aplicação de bases cromáticas. A área da lacuna a reintegrar corresponde a $0.04 \%$ da área total da pintura. Esquema gráfico de Ana Bailão. três simples. Para as 40 lacunas selecionadas estimaramse, aproximadamente, 2 horas e para a totalidade das lacunas, caso fosse esse o objetivo, estimaram-se 15 horas. Contudo, convém ter sempre presente, que esta previsão temporal varia em função da técnica de reintegração escolhida e da experiência do conservador-restaurador, responsável pela tarefa, sobretudo no que diz respeito à sua capacidade para misturar e diluir tintas, com vista ao acerto final da cor.

Uma das vantagens dos programas de sistemas de informação geográfica (SIG), em relação a outras ferramentas computacionais, é a possibilidade de se puder criar uma base de dados, que neste caso possibilita a descrição pormenorizada e personalizada de cada lacuna. Pode-se agregar informação do projeto numa tabela alfanumérica, designada em SIG de "tabela de atributos", que foi criada durante o processamento de dados em QGIS. À tabela de base adicionou-se ainda mais duas colunas, uma para o registo da técnica de reintegração, e outra para a anotação dos materiais e misturas que foram usados para obtenção dos matizes [tabela 6], podendo esta informação ser utilizada no relatório ou consultada no futuro.

A informação obtida com esta ferramenta revelou-se uma mais-valia porque ajuda a fundamentar algumas das tomadas de decisão pertinentes na fase de reintegração cromática, associadas ao rigor da descrição do método e ao tempo aproximado de intervenção. Obviamente que, em contexto de relatório técnico, toda a informação adquirida poderá ser também apreciável para a caracterização da área original da obra e da área não original (intervencionada pelo conservador-restaurador), assim como pode servir de apoio a posteriores intervenções e a consequentes tomadas de decisão.

Como último reparo, convém salientar que o ensaio aplicado na pintura não contemplou as lacunas de desgaste ou abrasão, do tipo I e II (Mora, Mora, Philippot, 1984: 305315). Não obstante o facto do processo de análise para esse tipo de lacunas poder vir a ser semelhante, como o que foi apresentado, por uma questão de simplificação
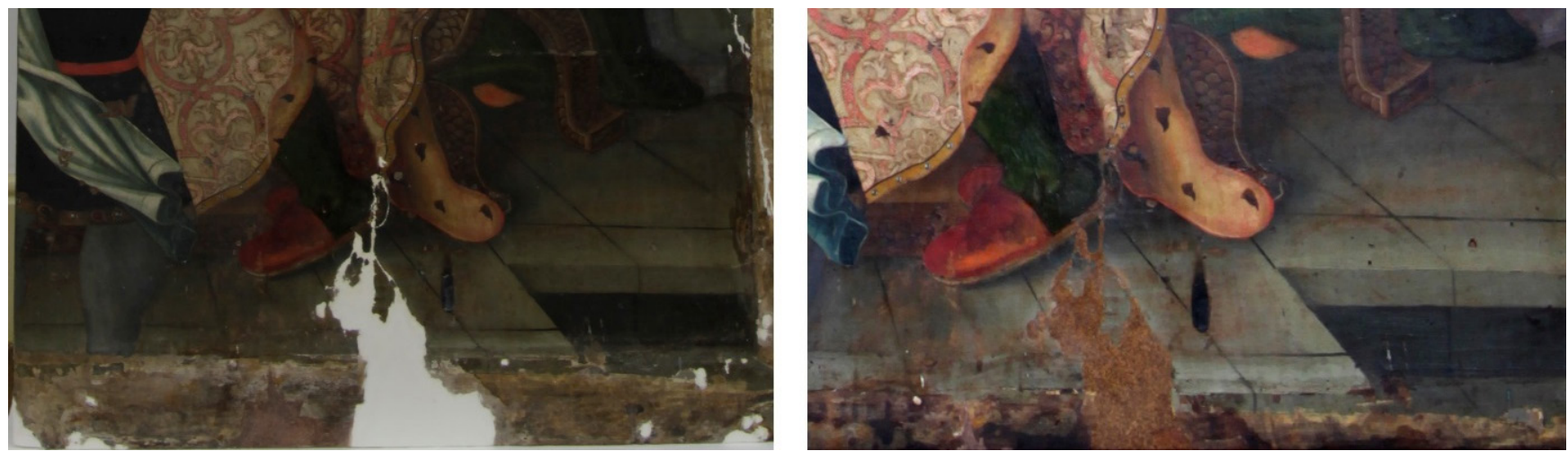

Figura 9- Visualização da lacuna n. ${ }^{\circ} 243$, a de maiores dimensões, antes (esquerda) e depois (direita) da aplicação de uma base ao tom da madeira. 


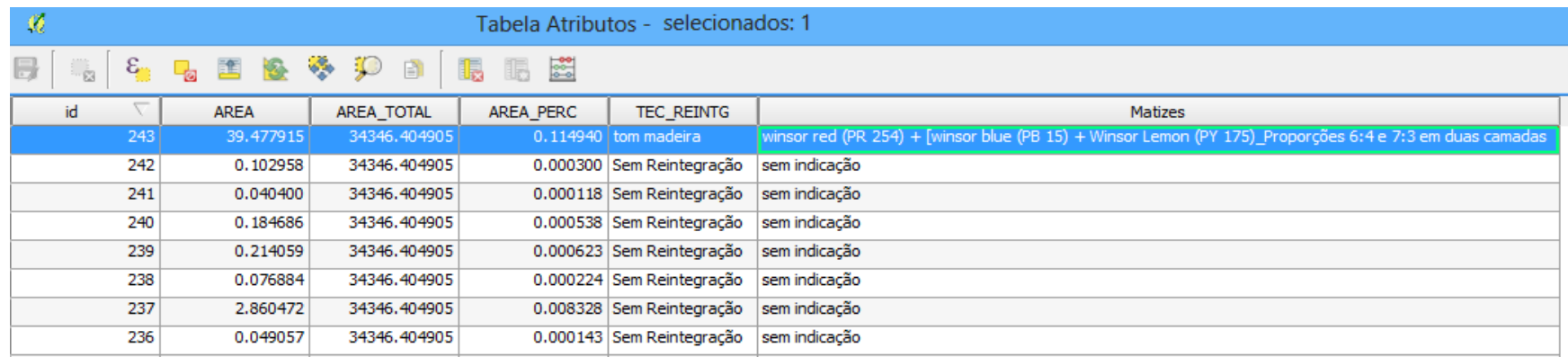

Tabela 6- Tabela de atributos que contém a informação associada às lacunas, em destaque, como exemplo, a n. ${ }^{\circ} 243$, a técnica de reintegração e os procedimentos e materiais utilizados. Tabela elaborada por Ana Bailão.

e clarificação do método sugerido, prevê-se fazer esse estudo noutra abordagem, em desenvolvimentos futuros.

\section{Conclusão}

O processo apresentado, dedicado à vertente da Documentação dos Bens Culturais aplicada às reintegrações cromáticas, poderá constituir uma estratégia para a análise quantitativa e qualitativa das obras. Isto significa que, para além de servir de método de registo, poderá influênciar a escolha da área a reintegrar, assim como contribuir para a organização do orçamento final de uma intervenção.

O método de documentação e análise exposto em modo de ensaio, poderá ser um sistema de apoio essencial para o conservador-restaurador, quer no diagnóstico, quer no planeamento da intervenção e durante o processo de reintegração. Embora possa contribuir decididamente para a tomada de decisão, a apreciação e avaliação do projeto deverá ser sempre multifatorial, e ter em linha de conta múltiplas vertentes, desde a opinião do proprietário da obra e o seu contexto sócio-cultural, assim como fatores bem conhecidos pelo conservador-restaurador: os atributos da cor, o formato da lacuna, os matizes a utilizar, a caracterização dos tons de sombra e de luz, o reconhecimento da anatomia das figuras, entre outros.

Contudo, após se superarem as dificuldades nas estratégias técnico-cientificas da operação de reintegração cromática, além da formação adequada do conservador-restaurador, talvez seja importante referir que a definição dos critérios éticos e deontológicos das intervenções constitui sempre o maior desafio dos projetos. $E$, além disso, não menos importante deverá ser o contínuo papel pedagógico das intervenções, junto dos fruidores de património, de modo a cultivar a importância do papel do conservadorrestaurador no enquadramento da lei, na sociedade e da sua participação direta no processo da tomada de decisão junto dos donos de obra.

\section{Agradecimentos}

Este estudo teve o apoio da Fundação para a Ciência e a Tecnologia (FCT) e QREN - POPH, co-financiado pelo Governo Português e União Europeia através do MCTES. Esta investigação foi financiada pelas bolsas de estudo da FCT: SFRH/BD/69783/2010 e SFRH/BPD/99163/2013.

\section{Notas}

[1] O tratteggio é um sistema de reintegração cromática elaborado com linhas verticais. Os primeiros traços verticais, que podem indicar o tom básico da reintegração, são sempre paralelos com intervalos regulares e equidistantes. Esses traços são muito importantes porque servem de linhas de referência para as cores que se seguem. Após essa primeira fase, sobre essas linhas fazem-se novos traços de cor pura ou com a mistura de cores. No intervalo dos traços aplicam-se as misturas de cores sobre a forma de velatura.

[2] Imprimadura: se bem que seja um vocábulo não muito comum em português, usamos a terminologia "imprimidura" como tradução da palavra italiana "imprimitura". Isto é, uma camada de cor que se aplica sobre o preparo, antes da aplicação da camada cromática (Cruz, 2006: 76). Acerca da utilização do vocábulo consultar a obra de Francisco Assis Rodrigues, Diccionario Technico e Historico de Pintura, Esculptura, Architectura e Gravura. Lisboa: Imprensa Nacional, 1875, p. 224.

[3] O princípio básico da seleção cromática é seguir as formas da composição através da aplicação de traços curtos e pequenos de cores puras (não misturadas na paleta) em camadas sucessivas, justapondo e sobrepondo de tal modo que, à distância, o efeito da cor reintegrada seja equivalente ao original. São usadas aguarelas ou pigmentos em pó aglutinados em verniz e, em teoria, apenas as cores primárias e secundárias, ocasionando o fenómeno da mistura ótica da cor (Casazza 1981: 30-32; Scarzanella e Cianfanelli 1992: 203). Na prática podem ser utilizadas todas as cores disponíveis, desde que sejam puras, à exceção do branco (este forçosamente presente na camada de nivelamento da lacuna, como fundo liso e refletor), por quebrar a transparência dos tons (Casazza 1981: 30, 34-63, Bailão, 2011: 54).

[4] A abstração cromática resulta da sobreposição sucessiva de camadas de cores puras sob a forma de curtos traços, 
ligeiramente encurvados e espontâneos. Todavia, a orientação dos traços varia da primeira à quarta camada (Casazza 1981:68). Os tons são combinados para criar uma opção quente e outra fria (Casazza 1981:67; Bailão, 2011: 57).

[5] O processo de georreferenciação inicia-se com a atribuição de coordenadas $\mathrm{X}$ e $\mathrm{Y}$ da imagem de referência. Estas correspondem a pontos de controlo a partir dos quais se consegue ter uma indicação métrica da área da imagem. Com a imagem georreferenciada é possível verificar a localização exata dos fenómenos presentes na superfície, as suas coordenadas e, em suma, caracterizar espacialmente a imagem.

[6] Esta obra foi objeto de dissertação de Susana Catarina Silva Mendes, para obtenção do grau académico de Mestre em Conservação e Restauro, na Escola das Artes, Universidade Católica Portuguesa. Acerca da pintura ver a seguinte obra: BRANDÃO, Domingos de Pinho (1984). Obra de Talha Dourada, Ensamblagem e Pintura na cidade e na Diocese do Porto. Documentação I - Séculos XV a XVII. Porto: Diocese do Porto, 168-169.

[7] As primeiras experiências documentadas de modo sistemático de análise métrica e espacial em património, recorrendo a ferramentas dos Sistemas de Informação Geográfica (SIG), remontam a 1999: SCHMID, W., ed. (2000). GRADOC: Graphic Documentation Systems in Mural Painting Conservation. Research Seminar Rome 16-20 November 1999. Roma: ICCROM. Outros estudos se seguiram, sobretudo em arqueologia e pintura mural. Mais recentemente, em contexto nacional, foram feitas aplicações de SIG e processamento digital sobre superfícies pictóricas: PIRES, H., MARQUES, P., HENRIQUES, F., OLIVEIRA, R. (2007). "Integrating laser scanning, multispectral imagery and GIS in C\&R documentation practices: A first approach using two XVIth century wood paintings from Convento de Cristo in Tomar". En XXI International CIPA Symposium, 01-06 October 2007, Athens, Greece; HENRIQUES, F. GONÇALVES, A. BAILÃO, A. (2009). "Tear feature extraction with spatial analysis: A thangka case study". Estudos de Conservação e Restauro, 1: 11-23; HENRIQUES, F., GONÇALVES, A. (2010). "Identificação de regiões de lacunas numa pintura retabular: análise comparativa de métodos de classificação em ambiente SIG". Estudos de Conservação e Restauro, 2: 72-81; HENRIQUES, F., GONÇALVES, A. (2010). "Analysis of Lacunae and Retouching Areas in Panel Paintings Using Landscape Metrics". En EuroMed 2010, Lecture Notes in Computer Science (LNCS), 6436: 99-109; HENRIQUES, F., GONÇALVES, A., CALVO, A. (2010). "Caracterização da densidade das lacunas em superfícies pictóricas com recurso a Sistemas de Informação Geográfica (SIG)". Conservar Património, 11: 3 - 11; FUENTES PORTO, A. (2010). Los Sistemas de Información Geográfica aplicados al estudio de las superficies pictóricas. Valência: Universidad Politécnica de Valencia. Dissertação de Mestrado; HENRIQUES, F., GONÇALVES, A., CALVO, A., BAILÃO, A. (2011). "Identificazione di lacune di un dipinto dopo la stuccature e prima del ritocco pittorico". En VCongresso Internazionale "Colore e Conservazione", Le fasi finali nel restauro delle opere policrome mobili. Cesmar7, Saonara: II Prato, 234-236; HENRIQUES, F.
(2012). Metodologias de Documentação e Análise Espacial em Conservação de Pintura. Porto: Escola das Artes, Universidade Católica Portuguesa. Doutoramento em Conservação de Pintura; ROQUE, D., MENDES, M., PEREIRA, S., FONSECA, A., MIMOSO, J. M. (2012)."Deteção de Anomalias em Azulejos através de Técnicas de Processamento Digital de Imagem". En Proceedings Congresso Internacional AZULEJAR 2012. Aveiro: Universidade de Aveiro; Departamento de Engenharia Civil; ROQUE, D., FONSECA, A., MIMOSO, J. M. (2013). "Mapeamento Digital e Classificação de Anomalias em Paramentos Murais: Processamento Digital de Imagem e Classificação Orientada por Objetos". En Proceedings Segundo Encontro Luso-Brasileiro de Conservação e Restauro. São João Del Rei; Brazil: Universidade Federal de São João Del Rey; FONSECA, A., ROQUE, D. PEREIRA, S., MENDES, M., MIMOSO, J. M. (2015). “Digital Image Processing: application to automatic classification of tile panel pathology". En International Conference Glazed Ceramics in Architectural Heritage (GlazeArch 2015). Lisboa: Laboratório Nacional de Engenharia Civil, 154-159.

[8] O programa informático QGIS 2.6. (QGIS), assim como todos os programas de SIG, têm a possibilidade de editar tabelas e de colocar as percentagens por ordem crescente, permitindo selecionar as regiões (lacunas) em função da ordem de grandeza dos valores, à qual pode ser atribuída uma escala de cor. Vd. QGIS, "A Free and Open Source Geographic Information System". http://www.qgis.org/en/site/. [09/07/2015]; QGIS, "Guia do utilizador do QGIS", em Documentação do QGIS 2.8. http://docs.qgis.org/2.8/pt_PT/docs/user_manual/. [09/07/2015].

[9] A escala de cores é disponibilizada pelo programa Quantum Gis 2.6. Existem várias escalas, motivo pelo qual, fica ao critério do operador a eleição de uma escala cromática especifica.

[10] Vd. BRANDI, C. (1961). "II Trattamento delle lacune della gestalt psychologie". En XX International Congress of History of Art. Nova lorque: [s.n.], pp. 149, 150; BAILÃO, A. (2010). “O gestaltismo aplicado à reintegração cromática de pintura de cavalete". Estudos de Conservação e Restauro. 1: 128-139.

[11] A tomada de decisão sobre a reintegração desta obra foi realizada em grupo. Foram tido em consideração vários fatores tais como o valor simbólico e a função da obra, a extensão e localização das lacunas, as referências cromáticas e formais em torno das lacunas, entre outros. Respostas a estas e outras questões podem ser consultadas na tese de doutoramento de BAILÃO, A. M. dos S. (2015). Critérios de intervenção e estratégias para a avaliação da qualidade da reintegração cromática em pintura. Porto: Universidade Católica Portuguesa, em Apêndice III.

[12] O termo "bases cromáticas" pode ser utilizado na conservação e restauro para caracterizar a primeira fase da reintegração cromática. Pode ser plana ou sob a forma de traços ou pontos. Sobre essa camada, efetuada num sistema aquoso, a aguarela ou gouache, segue-se a aplicação da camada de proteção (verniz), e a finalização, por exemplo, com pigmentos em pó e verniz. 


\section{Bibliografia}

BALDINI, U. (1998). Teoria de la restauración. Madrid: Editorial Nerea, Vol. 2.

BAILÃO, A. (2010). "O gestaltismo aplicado à reintegração cromática de pintura de cavalete", Estudos de conservação e restauro, 1: 128-139.

BAILÃO, A. (2011). "As Técnicas de Reintegração Cromática na Pintura: revisão historiográfica", Ge-Conservación, 2: 45-63.

BAILÃO, A. (2015). Critérios de intervenção e estratégias para a avaliação da qualidade da reintegração cromática em pintura. Porto: Universidade Católica Portuguesa. Tese de doutoramento.

BRANDÃO, D. P. de (1984). Obra de Talha Dourada, Ensamblagem e Pintura na cidade e na Diocese do Porto. Documentação I Séculos XV a XVII. Porto: Diocese do Porto, 168-169.

BRANDI, C. (1961). "II Trattamento delle lacune della gestalt psychologie". En XX International Congress of History of Art, Nova lorque: [s.n.], 149-150.

CASAZZA, O. (1981). Il restauro pittorico nell'unità di metodologia. Florença: Nardini Editore.

CRUZ, A. J. (2006). "Sobre o uso e o desuso de alguns termos relacionados com os materiais constituintes das obras de arte", Conservar Património, 3-4: 76.

CIATTI, M. (2009). "Appunti sulla storia del restauro pittorico in Italia". En Lacuna, Riflessioni sulle esperienze dell'Opificio delle Pietre Dure, Florença: Edifir - Edizioni Firenze.

FONSECA, A., ROQUE, D., PEREIRA, S., MENDES, M., MIMOSO, J. M. (2015). "Digital Image Processing: application to automatic classification of tile panel pathology". En International Conference Glazed Ceramics in Architectural Heritage (GlazeArch 2015). Lisboa: Laboratório Nacional de Engenharia Civil, 154159.

FUENTES PORTO, A. (2010). Los Sistemas de Información Geográfica aplicados al estudio de las superficies pictóricas. Valência: Universidad Politécnica de Valencia. Dissertação de Mestrado.

HENRIQUES, F., GONÇALVES, A., BAILÃO, A. (2009). “Tear feature extraction with spatial analysis: A thangka case study", Estudos de Conservação e Restauro, 1: 11-23.

HENRIQUES, F., GONÇALVES, A., BAILÃO, A., CALVO, A. (2009). "A lacuna pictórica: metodologias de interpretação e análise", Pedra e Cal. 11, 42: 13-15.

HENRIQUES, F., GONÇALVES, A. (2010). “Identificação de regiões de lacunas numa pintura retabular: análise comparativa de métodos de classificação em ambiente SIG", Estudos de Conservação e Restauro, 2: 72-81.
HENRIQUES, F., GONÇALVES, A. (2010). "Analysis of Lacunae and Retouching Areas in Panel Paintings Using Landscape Metrics", En EuroMed 2010, Lecture Notes in Computer Science (LNCS), 6436: 99-109.

HENRIQUES, F., GONÇALVES, A., CALVO, A., BAILÃO, A. (2011). "Identifcazione di lacune di un dipinto dopo la stuccature e prima del ritocco pittorico". En $V$ Congresso Internazionale "Colore e Conservazione", Le fasi finali nel restauro delle opere policrome mobili, Cesmar7, Saonara, II Prato, 234-236.

HENRIQUES, F. J. R. (2012). Metodologias de documentação e análise espacial em conservação de pintura. Porto: Universidade Católica Portuguesa. Doutoramento em Conservação de Pintura.

HENRIQUES, F., GONÇALVES, A., CALVO, A. (2010). “Caracterização da densidade das lacunas em superfícies pictóricas com recurso a Sistemas de Informação Geográfica (SIG)", Conservar Património, 11: 3-11.

MORA, P., MORA, L., PHILIPPOT, P. (1984). Conservation of wall paintings. Londres, Boston: Butterworths, 301-312.

PHILIPPOT, A., PHILIPPOT, P. (1959). “Le problème de l'intégration des lacunes dans la restauration des peintures", Bulletin de I'Institut Royal du Patrimoine Artistique. Bruxelas: IRPA. Vol. 2 (1959), p. 5.

PIRES, H., MARQUES, P., HENRIQUES, F., OLIVEIRA, R. (2007). "Integrating laser scanning, multispectral imagery and GIS in C\&R documentation practices: A first approach using two XVIth century wood paintings from Convento de Cristo in Tomar". En XXI International CIPA Symposium, 01-06 October 2007, Athens, Greece.

QGIS, "A Free and Open Source Geographic Information System", http://www.qgis.org/en/site/ [09/07/2015].

QGIS, "Guia do utilizador do QGIS", em Documentação do QGIS 2.8", http://docs.qgis.org/2.8/pt_PT/docs/user_manual/ [09/07/2015].

RODRIGUES, F. A. (1875), Diccionario Technico e Historico de Pintura, Esculptura, Architectura e Gravura, Lisboa: Imprensa Nacional, 224.

ROQUE, D., MENDES, M., PEREIRA, S., FONSECA, A., MIMOSO, J. M. (2012)."Deteção de Anomalias em Azulejos através de Técnicas de Processamento Digital de Imagem". En Proceedings Congresso Internacional AZULEJAR 2012. Aveiro: Universidade de Aveiro; Departamento de Engenharia Civil.

ROQUE, D., FONSECA, A., MIMOSO, J. M. (2013). “Mapeamento Digital e Classificação de Anomalias em Paramentos Murais: Processamento Digital de Imagem e Classificação Orientada por Objetos". En Proceedings Segundo Encontro Luso-Brasileiro de Conservação e Restauro. São João Del Rei; Brazil: Universidade Federal de São João Del Rey. 
SCARZANELLA, C. R.; CIANFANELLI, T. (1992). “La percezione visiva nel restauro dei dipinti. L'intervento pittorico". En Problemi di restauro. Riflessioni e ricerche, CIATTI, M. ed., Florença: EDIFIR, 185-211.

SCHMID, W. ed. (2000). GRADOC: Graphic Documentation Systems in Mural Painting Conservation. Research Seminar Rome 16-20 November 1999. Roma: ICCROM.

\section{Manuscrito:}

Lisboa, Arquivo Nacional da Torre do Tombo (Portugal), Registo das Visitações Gerais da Ordem de Malta à Comenda de Rossas, 1718-1719, livro 17, fl. 68 ss.

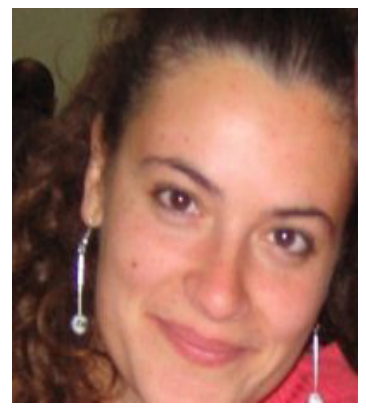

\section{Ana Bailão}

ana.bailao@gmail.com

Universidade Católica Portuguesa

Conservadora-restauradora em Pintura de cavalete. Doutoranda na Universidade Católica Portuguesa (UCP). Obtenção do grau de Mestre com o tema "Metodologia e técnicas da reintegração cromática em pintura de cavalete" pela mesma instituição. Licenciatura pré-Bolonha, pelo Instituto Politécnico de Tomar (IPT).

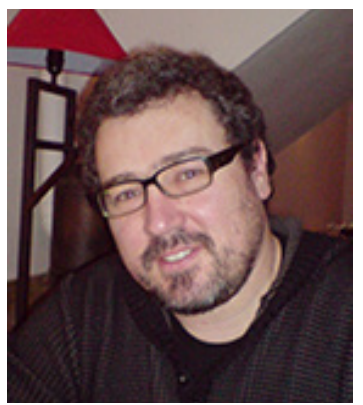

\section{Frederico Henriques}

frederico.painting.conservator@gmail.com Universidade Católica Portuguesa

Conservador-restaurador na especialidade de pintura, bacharel pela Escola Superior de Conservação e Restauro (1997), licenciatura pré-Bolonha no Instituto Politécnico de Tomar (2005), doutoramento em Conservação de Pintura pela Escola das Artes, da Universidade Católica Portuguesa (2013) e pós-doutorando no Centro de Investigação em Ciência e Tecnologia das Artes (CITAR), e no Laboratório HERCULES, da Universidade de Évora. Atualmente é bolseiro da Fundação para a Ciência e Tecnologia (FCT) e dedica-se exclusivamente à documentação digital de Bens Culturais. 


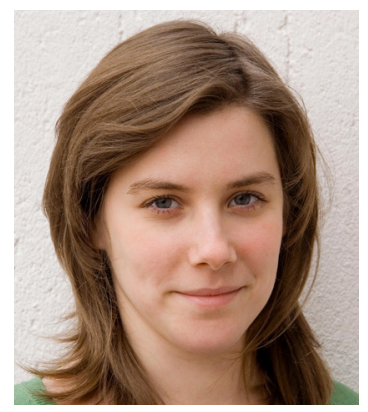

\section{Susana Mendes}

susmendes@gmail.com

Universidade Católica Portuguesa

Conservadora-restauradora. Licenciatura em Conservação e Restauro pela Escola das Artes, da Universidade Católica Portuguesa (2011) e Mestrado em Conservação e Restauro de Bens Culturais - Especialização em Pintura pela Escola das Artes, da Universidade Católica Portuguesa (2015). Principais interesses: Conservação e restauro de pintura sobre madeira, história da conservação e restauro, iconografia e iconologia.

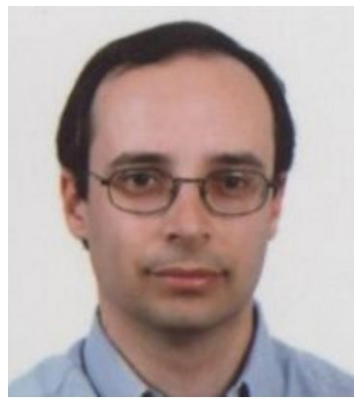

\section{Alexandre Gonçalves}

alexandre.goncalves@tecnico.ulisboa.pt

Instituto Superior Técnico, Universidade de Lisboa

Licenciado em Matemática Aplicada e Computação (1995, IST), mestre em Sistemas de Informação Geográfica (1998, IST) e doutorado em Engenaria do Território (2007, IST). É professor no Instituto Superior Técnico (IST). Os seus intereses científicos incluem Sistemas de Informação Geográfica, Análise Espacial, Otimização, Modelação Geográfica, Algoritmos para Dados Espaciais e aplicações genéricas de SIG, incluindo aplicações à arte e às reconstruções históricas. 